\title{
PERLINDUNGAN HUKUM PASAR TRADISIONAL DI SURAKARTA
}

\author{
Handoyo \\ Dinas Pengelolaan Pasar Surakarta
}

\begin{abstract}
$T$ his article is the result of research that answers the problems factors occurring between traditional and modern markets in Surakarta and the formulation of a model settlement of the problem. This study is exploratory research with the Juridical Sociological Approach. Legally, this study refers to the legislation on the protection of traditional markets, while sociologically this study refers to the effectiveness of the application and the problems that occur at the sites. This study uses literature study and interviews with officials of the Department of Market Management and Traditional Market Traders were selected through purposive sampling in the city of Surakarta. The research location in Surakarta is by selecting 17 (seventeen) common market as a sample representing other markets. The conclusion of this research is there are two factors that cause conflict in the traditional market Surakarta. First, the existence of violations of the rules in the Regulation No. 5/2011 on the structuring and development of shopping centers and modern stores which resulted in conflicts between traditional market traders as well as with the people around. Second, the superior and inferior elements generate a gap (the gap) between traditional and modern market and lead to conflict. A preventive method is used to resolve the conflict between the traditional and modern markets is a modern market must comply with applicable regulations, selling merchandise with different types in the traditional markets, have a good working relationship with traditional traders and small traders around, and limiting the hours of operation, While repressive ie closing places of business when it has not been complied with in the establishment of the modern market.
\end{abstract}

Keywords: Legal protection, the traditional market, modern market

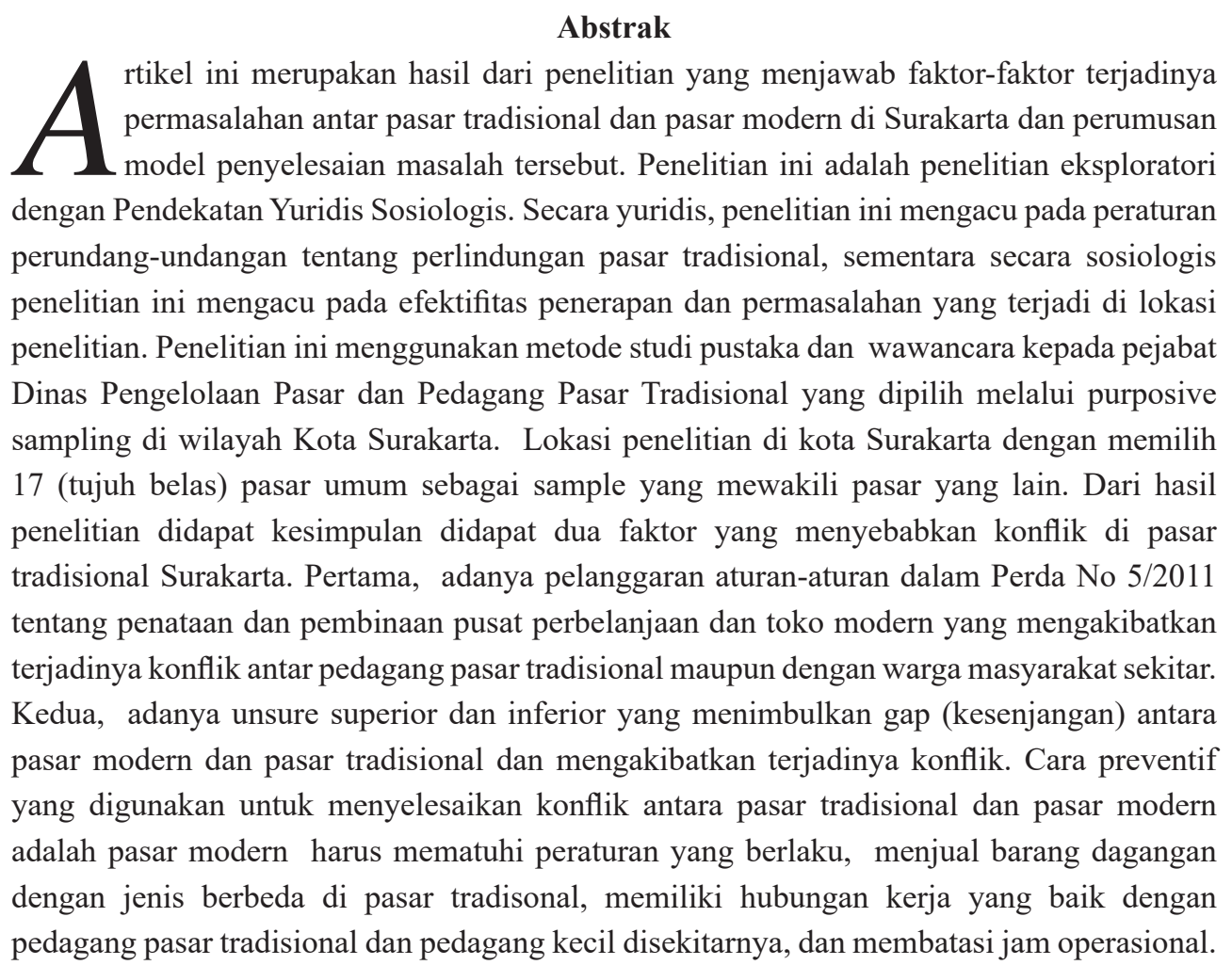


Sedangkan secara represif yaitu menutup tempat usaha ketika belum memenuhi ketentuan dalam pendirian pasar modern.

Kata kunci: Perlindungan hukum, pasar tradisional, pasar modern

\section{Pendahuluan}

Pasar merupakan sebuah tempat berkumpulnya para penjual dan pembeli dalam melakukan transaksi jual beli. Pada jaman dahulu, pasar tradisional merupakan satu-satunya tempat dimana masyarakat dari berbagai kalangan bertransaksi dan berbelanja keperluan sehari-hari. Hal tersebut menjadikan pasar tradisional sebagai ikon perekonomian masyarakat, karena dinilai mampu meleburkan tingkat kesenjangan sosial antar masyarakat, baik kalangan atas, menengah maupun bawah yang memiliki kepentingan dan tujuan yang sama. Selain itu, keberadaan pasar tradisional dinilai lebih merakyat dibandingkan pasar modern, karena pasar tradisional akan lebih banyak menyerap dan memberdayakan sumber daya manusia masyarakat sekitar, sehingga secara tidak langsung hal tersebut akan menunjang perekonomian masyarakat sekitar.

Akan tetapi, apabila diamati secara terperinci saat ini keberadaan pasar tradisional sedang dalam keadaan yang mengkhawatirkan dengan berbagai persoalan yang ada di dalamnya baik secara internal maupun eksternal. Permasalahan internal yang sering dijumpai yaitu kondisi bangunan pasar yang cenderung terlihat mengkhawatirkan dengan minimnya fasilitas umum seperti jumlah toilet dan WC, kurangnya sistem keamanan yang mengakibatkan banyaknya pencopet atau pencuri kendaraan, jumlah penerangan yang sangat kurang, dan akses jalan yang kurang teratur. Di samping itu, pola pemikiran para pedagang dan manajemen pasar yang masih tradisional mengakibatkan pasar tradisional tertinggal dari pasar modern. Sementara itu, persoalan eksternal yang terjadi yaitu pesatnya pertumbuhan pasar modern menjadikan pasar tradisional semakin terpinggir. Keberadaan pasar modern seperti mal, supermarket dan pusat perbelanjaan lainnya akan mengalahkan eksistensi pasar tradisional tersebut.

Secara rasional, konsumen akan lebih memilih tempat belanja yang bersih, besar, aman, bangunan yang megah serta fasilitas yang lebih modern dan canggih. Menurut Usman Hidayat salah satu hal yang menyebabkan terus berkembangnya pasar modern sekaligus mematikan pasar tradisional adalah preferensi konsumen. Faktor preferensi konsumen dalam mengalihkan tempat belanja dari pasar tradisional ke pasar modern memang dipandu oleh pilihan rasional, yaitu harga yang lebih rendah, lebih terjaminnya kualitas atas barang yang dibeli, dan tempat yang lebih nyaman. ${ }^{1}$

Saat ini, keberadaan pasar tradisional semakin mengalami penurunan dengan banyaknya jumlah pasar modern. Berdasarkan data dari Kementerian Perindusrian (Kemenpeerin) pada tahun 2007 dan Kementrian Perdagangan (Kemendag) pada tahun 2011 jumlah pasar tradisional di Indonesia mengalami penurunan cukup drastis dari tahun 2007-2011. Pada tahun 2007, jumlah pasar tradisional di Indonesia mencapai 13.450. Namun, pada tahun 2011, jumlahnya tinggal 9.950 "Jumlah Pasar tradisional berkurang lebih dari 3 ribu selama periode 2007-2011. Pada waktu yang bersamaan, Asosiasi Pengusaha Ritel Indonesia (Aprindo) juga merilis kenaikan jumlah retail modern yang cukup signifikan tahun 2007-2011. Kenaikannya hampir 8 ribu retail modern. Lambat laut pasar tradisional makin terpuruk dan dilibas oleh pasar modern demikian dinyatakan oleh Tino Rahardian (Sekjen IKAPPI). ${ }^{2}$ Sementara itu, jumlah pasar tradisional di Surakarta juga telah mengalami penurunan yang signifikan menurut Fauzi Sukri (Joglosemar, 19 November 2015) Data pada Badan Penanaman Modal dan Perijinan Terpadu Kota Surakarta (BPMPT) sejak tahun 2006 sampai dengan 2012 jumlah minimarket di Surakarta telah mencapai

1 Usman Hidayat, Preferensi Konsumen: Strategi Pengembangan Pasar Tradisional, Institute for Development of Economics and Finance (INDEF), Jakarta-IndonesiaISSN: 1410-2625, Volume 9 Nomor 2, April 2008

2 http://www.neraca.co.id/article/38397/ikappi-uu-perdagangan-lemahkan-pasar-tradisional 
48. Sementara itu, dari tahun 2012 sampai 2015 telah mencapai 70 minimarket. Pada saat ini terdapat 19 minimarket yang sedang mengantre untuk mengajukan perizinan. ${ }^{3}$ Hal tersebut berbanding terbalik dengan minimnya jumlah pasar tradisional di Surakarta yakni jumlah total sebanyak 44 (empat puluh empat) pasar tradisional.

Untuk menjaga eksistensi pasar tradisional agar tetap eksis dan tidak kalah saing dengan pasar modern diperlukan sebuah instrument yang dapat mengurus dan mengelola tatanan pasar tradisional yaitu instrument hukum. Dalam instrument ini, diperlukan suatu komitmen, kemauan, tanggung jawab dan political will pemerintah dan Negara. Menurut Jimly Asshiddiqie bahwa dalam konsep negara hukum kesejahteraan, negara dituntut untuk memperluas tanggung jawabnya kepada masalah-masalah sosial ekonomi yang dihadapi oleh rakyat banyak. Pemikiran demikianlah yang menjadikan legalisasi bagi penganut negara intervensionis pada abad 20 . Dalam berbagai masalah sosial dan ekonomi untuk menjamin terciptanya kesejahteraan bersama dan masyarakat kehadiran negara perlu dan bahkan harus melakukan intervensi. ${ }^{4}$

Pada hakekatnya penciptaan hukum adalah sebagai suatu sarana atau instrumen untuk mengatur hak-hak serta kewajiban-kewajiban subyek hukum. Namun pada perkembangannya hukum juga mempunyai yang lebih yaitu fungsi perlindungan. Hukum berfungsi sebagai perlindungan kepentingan manusia. Hukum berfungsi sebagai perlindungan kepentingan manusia. Agar kepentingan manusia terlindungi, hukum harus dilaksanakan menurut Sudikno Mertokusumo. ${ }^{5}$

Dengan perkembangan zaman, hukum memiliki fungsi yang lebih luas dalam masyarakat. Keberadaan hukum tidak hanya mengatur hak-hak dan kewajiban manusia, namun juga mampu menjadi pelindung yang berperan untuk melindungi segala kepentingan manusia.

\section{Rumusan Masalah}

1. Apa sajakah alasan terjadinya permasalahan antar pasar tradisional dan pas ar modern di Surakarta?

2. Bagaimanakah model penyelesaian kasus hukum tersebut?

\section{Metode Penelitian}

Penelitian dalam penulisan ini merupakan jenis penelitian eksploratori yaitu untuk mengungkap dan memperoleh pandangan baru tentang gejala atau permasalahan yang terjadi di suatu tempat yang nantinya dapat digunakan untuk merumuskan hipotesis dalam penelitian. Pendekatan Yuridis Sosiologis yaitu berfungsi untuk mengkaji masalah yang terjadi dimasyarakat atau penerapannya dalam kenyataan kemudian mengkaitkannya dengan peraturan perundangundangan yang berlaku. Dapat dijadikan arahan untuk menganalisa gejala hukum yang timbul dan kemudian hasil pembahasan yuridis tersebut akan diarahkan pada aspek sosiologis. ${ }^{6}$ Secara yuridis, penelitian ini mengacu pada peraturan perundang-undangan tentang perlindungan pasar tradisional, sementara secara sosiologis penelitian ini mengacu pada efektifitas penerapan dan permasalahan yang terjadi di lokasi penelitian.

Penelitian ini menggunakan metode: a) interview (wawancara) yaitu dengan mewawancara langsung pihak-pihak yang terkait dalam persoalan ini, yaitu pejabat Dinas Pengelolaan Pasar dan Pedagang Pasar Tradisional yang dipilih melalui purposive sampling di wilayah Kota Surakarta. b) Study pustaka yaitu dengan melihat dan mengkaji data-data kepustakaan dengan tujuan untuk membandingkan dan melengkapi data-data yang ada dalam jurnal, artikel, buku, dan dokumen ilmiah terkait dengan penelitian yang dibahas.

3 M Fauzi Sukri, Pasar Minimarket,Joglosemar,19 November 2015

4 Jimly Assiddiqie, Gagasan Kedaulatan Rakyat Dalam Konstitusi Dan Pelaksanaannya Di Indonesia, , Jakarta , PT Ichtiar Baru Van Hoeve, hlm. 223

5 Sudikno Mertokusumo, Mengenal Hukum, Suatu Pengantar,Liberty, Yogyakarta, 1996, hlm 140

6 Bambang Waluyo, Penelitian Hukum Dalam Praktek, Sinar Grafika, Jakarta, 1991, hal 20 
Penelitian ini mengambil sampel di kota Surakarta dengan memilih 17 (tujuh belas) pasar umum sebagai sample yang mewakili pasar yang lain. Hal ini dikarena pasar tradisional merupakan icon perekonomian masyarakat di Surakarta dan sebagian besar masyarakatnya memperoleh penghasilan dari pasar tradisional. Selain itu, Surakarta merupakan kota yang strategis dan dinamis yang mana banyak ilmuan maupun praktisi yang berani mengajukan kritikan secara tegas mengenai kebijakan pemerintah terhadap peraturan hukum pasar tradisional.

\section{Hasil dan Pembahasan}

\section{Perlindungan Hukum}

Kota Surakarta merupakan salah satu kota yang mayoritas penduduknya adalah pedagang. Berdasarkan data terdapat 44 (empat puluh empat) pasar tradisional yang saat ini masih aktif beroperasi di Surakarta. Masing-masing pasar memiliki klasifikasi tersendiri yakni berdasarkan jenis dagangannya, pasar tradisional dibedakan menjadi dua yaitu pasar umum dan pasar khusus. Pasar tradisional diklasifikasikan menjadi 3 golongan, yaitu kelas I, kelas II dan kelas III. Masing-masing bentuk pasar tradisional yaitu sebagai berikut:

Tabel 4.1. Nama Pasar,Kelas dan Lokasi

\begin{tabular}{|c|c|c|c|}
\hline No. & PASAR & KELAS & ALAMAT PASAR \\
\hline (1) & (2) & (3) & (3) \\
\hline 1 & Legi & I A & Jl. Jend S Parman, Banjarsari (0271 669560) \\
\hline 2 & Klewer & I A & Jl. Dr. Rajiman, Pasar Kliwon (0271 635933) \\
\hline 3 & Singosaren & I A & Jl. Gatot Subroto, Serengan (0271 631770) \\
\hline 4 & Gede & I A & J1. Jend Urip Sumoharjo, Jebres (0271 635058) \\
\hline 5 & Nusukan & I A & Jl. Kapten P Tendean, Banjarsari \\
\hline 6 & Nongko & I A & Jl. RM Said, Banjarsari \\
\hline 7 & Harjodaksino & I B & Jl. Kom. Yos Sudarso, Serengan \\
\hline 8 & Jongke & I B & Jl. Dr. Rajiman, Laweyan \\
\hline 9 & Notoharjo & I B & Jl. Serang, Semanggi, Pasar Kliwon \\
\hline 10 & $\begin{array}{l}\text { Taman Pasar Burung dan } \\
\text { Ikan Hias Depok }\end{array}$ & I B & Jl. Balekambang Lor, Banjarsari \\
\hline 11 & Ngudi Rejeki Gilingan & I B & Jl. A.Yani Banjarsari \\
\hline 12 & Gading & II A & Jl. Veteran, Pasar Kliwon \\
\hline 13 & Rejosari & II A & Jl. Sindunatan, Jebres \\
\hline 14 & Pucangsawit & II A & Jl. Ir. Juanda Pucangsawit Jebres \\
\hline 15 & Purwosari & II A & Jl. Brigjend Slamet Riyadi, Laweyan \\
\hline 16 & Panggungrejo & II A & Jl. Panggungrejo Jebres \\
\hline 17 & Ngarsopuro & II A & J1. Ronggowarsito \\
\hline 18 & Sidodadi & II A & Jl. Brigjend Slamet Riyadi, Kleco, Laweyan \\
\hline 19 & Cinderamata & II A & Barat Alun - Alun Utara \\
\hline 20 & Ayu Balapan & II A & J1. Monginsidi, Banjarsari \\
\hline 21 & Mojosongo & II A & Jl. Brigjend Katamso, Jebres \\
\hline 22 & Ledoksari & II A & Jl. Jend. Urip Sumoharjo. Jebres \\
\hline 23 & Kadipolo & II A & Jl. Dr. Rajiman, Laweyan \\
\hline 24 & Tanggul & II B & Jl. RE Martadinata, Jebres \\
\hline 25 & Kabangan & II B & J1. Dr. Rajiman, Laweyan \\
\hline
\end{tabular}




\begin{tabular}{clll}
\hline No. & \multicolumn{1}{c}{ PASAR } & KELAS & \multicolumn{1}{c}{ ALAMAT PASAR } \\
\hline $\mathbf{( 1 )}$ & \multicolumn{1}{c}{$(\mathbf{2})$} & \multicolumn{1}{c}{$(\mathbf{3})$} & \multicolumn{1}{c}{ (3) } \\
\hline 26 & Penumping & II B & Jl. Sutowijoyo, Laweyan \\
27 & Ayam & II B & Jl. Serang, Semanggi, Pasar Kliwon \\
28 & Kliwon & II B & Jl. Kapten Mulyadi, Pasar Kliwon \\
29 & Jebres & II B & Jl. Prof W.Z. Yohanes, Jebres \\
30 & Kembang & II B & Jl. Dr Rajiman, Laweyan \\
31 & Mebel & II B & Jl. A. Yani, Jebres \\
32 & Triwindu & II B & Jl. Diponegoro, Keprabon, Pasar Kliwon \\
33 & Ngemplak & III A & Jl. A. Yani, Jebres \\
34 & Bangunharjo & III A & Jl. K.S. Tubun, Banjarsari \\
35 & Sidomulyo & III A & Jl. S. Parman, Banjarsari \\
36 & Elpabes & III A & Jl. R Saleh Banjarsari \\
37 & Sangkrah & III A & Barat Stasiun KA Sangkrah, Pasar Kliwon \\
38 & Tunggulsari & III A & Jl. Untung Suropati, Pasar Kliwon \\
39 & Jurug & III A & Jl. KH Maskur, Jebres \\
40 & Mojosongo P & III B & Jl. Sibela, Mojosongo, Jebres \\
41 & Ngumbul & III B & Jl. RM Said, Banjarsari \\
42 & Bambu & III B & Jl. Tentara Genie Pelajar Nusukan Banjarsari \\
43 & Besi & III B & Jl. Serang, Semanggi, Pasar Kliwon \\
44 & Joglo & III B & Jl. Kol Sugiyono Kadipiro Banjarsari \\
\hline & & &
\end{tabular}

Segala bentuk peraturan perundang-undangan akan ditetapkan oleh pemerintah daerah. Maka dari itu, segala bentuk kebijakan yang ditetapkan oleh pemerintah haruslah sesuai dengan kebutuhan dan kepentingan masyarakat. Dengan demikian, keberadaan pasar tradisional membutuhkan perlindungan hukum dari pemerintah. Segala bentuk perlindungan hukum di pasar tradisional di Surakarta yaitu sebagai berikut:

\section{Perlindungan Hukum Preventif}

\section{a. Produk Perlindungan}

Penetapan perlindungan hukum preventif bertujuan untuk melindungi keberadaan pasar tradisional di Surakarta. Aturan-aturan Hukum yang telah ditetapkan oleh pemerintah Pusat yaitu meliputi: UU No. 14 Tahun 2014, Perpres RI No. 112 Tahun 2007, Permendag RI 56/M-DAG/PER/9/2014,Permendagneg No. 70/M-DAG/PER/12/2013, dan Permendagneg RI No 20 Tahun 2012. Sedangkan aturan-aturan hukum yang ditetapkan di kota Surakarta yaitu mencakup Perda Kota Surakarta No 5 Tahun 2011, Perda Kota Surakarta No 1 Tahun 2010, Peraturan Walikota Surakarta No 3 Tahun 2013, Peraturan Walikota Surakarta No 17-A Tahun 2012, Surat Edaran (SE) Walikota Surakarta No $510 / 1519$.

Berdasarkan data penelitian di lapangan, terdapat beberapa perlindungan hukum yang diperoleh pasar tradisional di Surakarta yaitu antara lain:

1) Meningkatkan kualitas bangunan dan pengelompokan masyarakat;

2) Memberikan kemudahan akses perijinan dan perlindungan standarisasi pelayanan.

3) Memberikan kepastian hukum bagi pelaku pasar; 
4) Memberikan hak dan kebebasan yang sama bagi semua pedagang untuk memanfaatkan pasar dan mengembangkan usaha.

Bentuk perlindungan hukum tersebut berupaya untuk memberdayakan pasar tradisional sebagai ikon perekonomian bagi masyarakat dan juga untuk mempertahankan akuntabilitas pasar tradisional di kota Surakarta.

\section{b. Implementasi Perlindungan Hukum Preventif}

Untuk menerapkan aturan-aturan perlindungan hukum preventif, pemerintah mencanangkan beberapa program guna menunjang keberhasilan perlindungan hukum preventif tersebut, yaitu:

1) Revitalisasi dan Rehabilitasi Pasar Tradisional

Program revitalisasi pasar tradisional di kota Surakarta bertujuan untuk mengembangkan dan meningkatkan perekonomian rakyat. Hal ini dikarenakan pasar tradisional merupakan ujung tombak penghasilan masyarakat Surakarta, sehingga segala sesuatu dapat berubah apabila pasar tradisioanl mengalami penurunan.

Program-program di Pemerintah Kota Surakarta yang sudah diprogramkan khususnya untuk perlindungan pasar tradisional meliputi program-program fisik maupun non fisik. Untuk program fisik berkaitan dengan pemberdayaannya dan pengelolaanya, terdapat program revitaliasi dan rehabilitasi pasar dalam rangka pengembangan fisik pasar agar menjadi representatif.

Berdasarkan data yang diperoleh, DPP telah melakukan revitalisasi pada 17 (tujuh belas) bangunan pasar tradisional untuk meningkatkan daya saing pedagang kecil pada akhir tahun 2015. Berikut data revitalisasi pasar tradisional pada periode tahun 2006-2015

Tabel. 4.2. Revitalisasi Pasar Tradisional Kota Surakarta Tahun 2006-2015

\begin{tabular}{ccl}
\hline No & Tahun & \multicolumn{1}{c}{ Nama Pasar } \\
\hline 1 & 2006 & Nusukan, Klithikan Notoharjo, Mojosongo, Kembang \\
2 & 2007 & Sidodadi \\
3 & 2008 & Gading, Ngarsopuro \\
4 & 2009 & Triwindu, Pucangsawit, Panggungrejo \\
5 & 2010 & Ayu tahap I, Legi \\
6 & 2011 & Ayu tahap II \\
7 & 2012 & Taman Pasar Burung dan Ikan Depok, Turisari (Nongko) \\
8 & 2013 & Gilingan, Kliwon, Elpabes \\
9 & 2014 & Pasar Tanggul Tahap I \\
10 & 2015 & Pasar Tanggul \\
\hline
\end{tabular}

Sumber : Dinas Pengelolaan Pasar 2015

2) Pembinaan dan pelatihan

Pembinaan dan pelatihan kepada para pedagang dimaksudkan untuk meningkatkan kemampuan pedagang dalam manajemen pemasaran, penataan barang dagangan dan cara melayani konsumen secara ramah.

Pembinaan dan pelatihan merupakan program non fisik. Pembinaan dan pelatihan kepada pedagang sehingga pelaku pasar lebih ahli dan memiliki keahlian dalam bidang kewirausahaan. ${ }^{7}$

7 Erni, Susiatun, Ka Si Evaluasi, Pelaporan dan Pengendalian DPP Kota Surakarta. 
Program ini berlangsung sekali dalam setahun yang diselenggarakan oleh Dinas Pengelolaan Pasar. Akan tetapi, jumlah yang ikut dalam kegiatan ini masih sedikit karena anggaran dana yang ditetapkan oleh pemerintah belum mencukupi untuk pelatihan semua pedagang pasar. Berdasarkan data yang diperoleh, anggaran yang ditetapkan oleh pemerintah setiap tahunnya hanya mencakup untuk 100 pedagang saja, hal itumasih sangat jauh dengan jumlah keseluruhan pedagang di pasar tradisional.

\section{b. Legalisasi Usaha dan Tempat}

Lokasi dagang di pasar tradisional di bedakan menjadi 3 yaitu kios, los dan oprokan. Masing-masing penetapan dilakukan sesuai perda dalam UU dengan syarat-syarat tertentu. Bagi pemilik kios dan los maka wajib memiliki SHP (Surat Hak Penetapan). Penerbitan SHP dan KTTP (Kartu Tanda Pengenal Pedagang) ini merupakan beschikking dari pemerintah Surakarta yang isinya mencakup hak dan kewajiban pedagang.

Penerbitan SHP dan KTTP hanya ada di kota Surakarta, sementara berdasarkan Peraturan Menteri Dalam Negeri No 20 Tahun 2012 Pengelolaan Dan Pemberdayaan Pasar Tradisional bahwa pedagang yang memanfaatkan tempat usaha harus memiliki Surat Izin Tempat Usaha (SITU).

Untuk Program non fisik lainnya yaitu sebuah program tentang kepastian atau legalitas usaha pedagang dalam bentuk pemberian SHP dan KTTP kepada seluruh pedagang di pasar. $^{8}$

\section{c. Kebijakan Pendirian Pasar Modern}

Kebijakan Pemerintah Kota Surakarta mengenai pendirian pasar modern yaitu sesuai dengan Perda No 1 Tahun 2011 yang mengatur tentang pendirian pasar modern terkait dengan jarak, zonasi dan jenis dagangan.

Sesuai dengan perda No 5/2011 tentang Penataan dan Pembinaan Pusat Perbelanjaan dan Toko Modern, di antaranya minimarket wajib berjarak minimal 500 meter dari pasar tradisional. Perizinan pembangunan minimarket baru wajib dilengkapi izin usaha toko modern (IUTM).

\section{Perlindungan Hukum Represif}

Segala bentuk perlindungan para pedagang di pasar tradisional telah ada dalam Perda. Hal tersebut tidak terkecuali untuk izin pencabutan surat hak yang mana akan diberikan kepada pihak yang menggunakan kios/ took dan / los di pasar. Berdasarkan penelitian bahwa surat hak tersebut berupa Surat Hak Penempatan (SHP) yang telah disusun dalam Perda No 1 Tahun 2010 Pasal 27 mengenai tentang Pencabutan dan Penarikan SHP pada pasal 1.

Apabila Hak Penempatan tempat pedagang dicabut, maka mereka tidak memiliki hak untuk melawan atau keberatan atas tindakan Dinas Pengelolaan Pasar. Sementara bentuk sanksi yang akan diterima yaitu berupa teguran tertulis dan lisan selama tiga kali, kemudian pencabutan SHP dan/atau KTPP dan terakhir pengosongan tempat berdagang.

\section{Perlindungan Fungsional}

Bentuk perlindungan pasar yang dilakukan oleh Dinas Pengelolaan Pasar yaitu sebagai berikut:

a. Kebersihan Pasar

Aturan menjaga kebersihan pasar telah diatur dalam pasal 34 Perda No 1 Tahun 2010 yang menyatakan bahwa Dinas bertanggung-jawab untuk menciptakan kebersihan dan keindahan lingkungan pasar. Selain itu, untuk menjaga keamanan dan ketertiban maka 
diterbitkanlah SOP (Standar Operasional Pelayanan) mengenai keamanan dan ketertiban oleh Walikota.

b. Keamanan Dan Ketertiban Pasar

Menjaga keamanan dan ketertiban pasar merupakan komponen penting dikarenakan untuk menjaga kestabilan dan kenyamanan bagi para pedagang dan pembeli dalam bertransaksi di pasar. Hal ini telah diatur dalam pasal 34 Perda No 1 Tahun 2010. Selain itu, hal tersebut juga tercantum dalam SOP mengenai keamanan dan ketertiban.

c. Penyelenggaraan Air Bersih Dan Penerangan

Dinas perlu memberikan penyediaan air bersih dan penerangan untuk memelihara infrastruktur pasar tradisional. Bentuk fasilitas yang menunjang program ini yaitu seperti pengadaan lampu dan alat-alat listrik lainnya.

\section{Konflik Pasar Tradisional dan Pasar Modern}

\section{Konflik Pendirian Pasar Modern}

Banyaknya pasar modern yang telah berdiri di kota Surakarta memunculkan konflik antar pasar tradisional dan pasar modern. Hal tersebut dikarenakan pendirian pasar modern yaitu minimarket tersebut bertentangan dengan peraturan yang berlaku yaitu seperti ijin operasional dan jarak dengan pasar tradisional. Salah satu konflik yang telah terjadi yaitu antara minimarket di daerah Stasiun Balapan dengan pedagang pasar Ayu Balapan seperti yang telah diberitakan dibeberapa media selama ini.

\section{Faktor-faktor Penyebab Konflik}

\section{a. Yuridis Normatif}

Bentuk yuridis normative yang menyebabkan konflik antar pasar tradisional dan pasar modern yaitu tidak ditaatinya ketentuan Perda No 5/2011 tentang Penataan dan Pembinaan Pusat Perbelanjaan dan Toko Modern. Bahwa sesuai dengan ketentuan Perda No 5/2011 mensyaratkan semua ritel modern termasuk minimarket, harus berjarak minimal 500 meter dari pasar tradisional. Namun kenyataannya masih banyak ditemukan minimarket yang jaraknya kurang dari 500 meter.

Bagi minimarket yang hendak beroperasi 24 jam, maka posisinya harus terletak di jalan nasional dan jalan provinsi. Selain itu, minimarket yang beroperasi selama 24 jam juga harus terletak di lingkup Stasiun Pengisian Bahan Bakar Umum (SPBU) dan berada di kawasan Rumah Sakit. Sehingga ketika aturan-aturan tersebut di langgar maka akan menimbulkan konflik antar kedua belah pihak yakni pasar tradisional dan pasar modern.

\section{b. Sosiologis}

Konflik sosial timbul karena masyarakat terdiri atas sejunlah kelompok sosial yang mempunyai karakteristik yang berbeda satu sama lain. Masyarakat tersusun dalam kelompok dan strata sosial yang berbeda-beda. ${ }^{9}$

Apabila diamati secara mendalam jelas terlihat bahwa keberadaan pasar tradisional terlihat lebih lemah ketika dihadapkan langsung (head to head) dengan pasar modern. Timbulnya konflik antar pasar tradisional dan pasar modern dikarenakan adanya pertentangan kepentingan. Adanya kesenjangan antara superior dan inferior yang lamakelamaan nantinya akan memperbesar gap (kesenjangan) antara pasar modern dan pasar tradisional. Sehingga hal itu akan memperbesar potensi timbulnya konflik.

9 Wirawan, Konflik dan Manajemen Konflik (teori,Aplikasi dan Penelitian) Salemba Humanika, 2010, 


\section{Penyelesaian Konflik Pasar Tradisional dan Pasar Moder}

\section{Model Penyelesaian Konflik}

Cara penyelesaian konflik antara pasartradisional dan pasar modern diklasifikasikan menjadi dua bagian yaitu secara preventif dan persuasive. Secara preventif masyarakat diarahkan untuk menaati semua peraturan dan tidak melakukan pelanggaran.

Berdasarkan penelitian beberapa konflik yang muncul dapat diselesaikan dengan cara pendirian pasar modern yang tidak menyalahi peraturan yang telah ditetapkan, jenis barang yang dijual di pasar modern harus sesuai dengan pasar tradisional, memiliki hubungan yang baik dengan pasar tradisional dan pedagag kecil di sekitarnya dan membatasi jam operasional.

Sedangkan secara represif yaitu cara-cara yang dilakukan setelah pelanggaran terjadi. Tindakan represif yang dapat dilakukan yaitu menutup tempat usaha ketika belum memenuhi persyaratan dalam pendirian pasar modern.

\section{Upaya Pencegahan}

Upaya yang dapat dilakukan agar tidak terjadi konflik antara pasar tradisional dan pasar modern yaitu sebagai berikut:

a. Upaya dari aspek regulasi

Untuk mencegah terjadinya konflik antara pasar tradisional dan pasar modern yaitu dengan cara pengembangan dan peningkatan pemberdayaan (empowering) pedagang baik secara fisik maupun non fisik. Perlu adanya regulasi yang jelas dan tegas mengenai pendirian pasar modern.

Perlu adanya pembatasan jumlah pendirian pasar modern agar tidak mematikan keberadaan pasar tradisional. Selain itu, lokasi atau jarak antara pasar tradisional dan pasar modern harus diatur secara jelas untuk menghindari persaingan usaha yang terlalu frontal. b. Upaya dari aspek pelaksanaan

Penegakan hukum merupakan sebuah upaya yang dilakukan untuk menegakkan normanorma hukum secara nyata sebagai pedoman perilaku dalam lalu lintas atau hubunganhubungan hukum dalam kehidupan bermasyarakat dan bernegara. Penegakan hukum untuk melindungi keberadaan pasar tradisional dapat dilakukan baik dari sisi peningkatan pemberdayaan pasar tradisioanal baik secara fisik dan non fisik maupun regulasi pasar modern seperti masalah zonasi, jarak dan jam operasional.

\section{Penutup}

Pemerintah kota Surakarta telah mengupayakan bentuk perlindungan Hukum kepada pasar tradisional yaitu berupa perlindungan hukum preventif, represif dan fungsional. Bentuk perlindungan hukum preventif yaitu dengan adanya penetapan peraturan tentang pasar tradisional oleh pemerintah pusat. Penerapan yang dilakukan yaitu dengan dilaksanakannya program revitalisasi / rehabilitasi pasar tradisonal, legalisasi usaha pasar tradisional, dan kebijakan pedirian pasar modern. Sementara itu, bentuk penerapan hukum represif belum menunjukkan adanya hak bagi pedagang untuk mempertahankan dan membela diri atas perlakuan dari Dinas Pengelolaan Pasar dalam tindakan pencabutan SHP dan/atau KTPP dan pengosongan tempat berdagang.

Berdasarkan penelitian terdapat 2 faktor yang menyebabkan konflik di pasar tradisional Surakarta yaitu faktor juridis normatif dan sosiologis. Bentuk juridis normative yaitu dengan adanya pelanggaran aturan-aturan dalam Perda No 5/2011 tentang penataan dan pembinaan pusat perbelanjaan dan toko modern yang mengakibatkan terjadinya konflik antar pedagang pasar tradisional maupun dengan warga masyarakat sekitar. Sementara itu, adanya unsure superior dan inferior merupakan bentuk faktor sosiologis yang mengakibatkan terjadinya konflik. Konflik tersebut disinyalir karena adanya kesenjangan antara superior dan inferior yang akhirnya menimbulkan gap (kesenjangan) antara pasar modern dan pasar tradisional. 
Dalam hal ini, peran pemerintah sangat diperlukan untuk memperkecil gap dengan tujuan untuk mengangkat pasar tradisional supaya tidak semakin jauh tertinggal dengan pasar modern.

Cara yang digunakan untuk menyelesaikan konflik antara pasar tradisional dan pasar modern yaitu secara preventif dan persuasif. Model penyelesaian yang dapat dilakukan dalam menyelesaikan konflik tersebut yaitu pendirian pasar modern dengan mematuhi peraturan yang berlaku, menjual barang dagangan dengan jenis di pasar tradisonal, memiliki hubungan kerja yang baik dengan pedagang pasar tradisional dan pedagang kecil disekitarnya, dan membatasi jam operasional. Sedangkan secara represif yaitu menutup tempat usaha ketika belum memenuhi ketentuan dalam pendirian pasar modern.

\section{Daftar Pustaka}

Arikunto, Suharsimi. 2006. Prosedur Penelitian (Suatu Pendekatan Praktik). Jakarta: PT Rineka Cipta.

Arsyad, Lincolin. 2010. Ekonomi Pembangunan (Edisi Ke Lima). Yogyakarta : STIE YKPN.

Assiddiqie, Jimly. 1994. Gagasan Kedaulatan Rakyat Dalam Konstitusi Dan Pelaksanaannya Di Indonesia. Jakarta : PT Ichtiar Baru Van Hoeve.

Bungin, Burhan. 2003. Analisis Data Kualitatif. Jakarta: Raja Grafindo Persada.

Dinas Pengelolaan Pasar. 2012. Kumandangnya Pasar Tradisional. Surakarta

Echols, John M dan Hassan Shadily. 2003. Kamus Bahasa Inggris Indonesia (Cet. XXV). Jakarta: PT Gramedia.

Hadjon, Philipus M. 1987. Perlindungan Hukum Bagi Rakyat Indonesia, Sebuah Studi tetang prinsip-prinsipnya, Penanganannya oleh Pengadilan Dalam Lingkungan Peradilan Umum dan Pembentukan Peradilan Administrasi Negara. Surabaya : Bina Ilmu.

Harun., 2002. "Perlindungan Hukum Bagi Pedagang Di Pasar Tradisional Kartasura", Jurnal Penelitian Hukum UMS, ISSN 1411-4256, Vol 4, No 2, hal 109-120.

Hidayat, Usman Hidayat., 2008. "Preferensi Konsumen: Strategi Pengembangan Pasar Tradisiona"l, Institute for Development of Economics and Finance (INDEF), JakartaIndonesiaISSN: 1410-2625, Vol 9 No 2.

Itagaki, Yoichi., 1960. "Some Notes On The Controversy Concerning Boeke "Dualistic Theory" :Implicationas For The Theory Of Economic Development In Underdeveloped Countries", Hitotsubashi Journal of Economic, Vol 1, No 1.

Kamus Besar Bahasa Indonesia. 2005. Jakarta: Balai Pustaka.

Kumilausari, Sinta Tri. 2009. Strategi DPP Kota Surakarta Dalam Mengoptimalkan Penerimaan Restribusi Pasar Tahun 2008 Melalui Pemberdayaan Pasar Tradisional. Surakarta

Kusnadi. 2002. Masalah Kerja Sama, Konflik dan Kinerja. Malang: Taroda.

Lauer, Robert H.,. 2001. Perspektif Tentang Perubahan Sosial. Jakarta : PT. Rineka Cipta.

Lawang,Robert. 1994. Buku Materi Pokok Pengantar Sosiologi. Jakarta: Universitas Terbuka.

Moleong, Lexy. J.,. 2009. Metode Penelitian Kualitatif (Edisi Revisi). Bandung: Remaja Rosdakarya.

Narwoko, J. Dwi dan Bagong Suyanto. 2006. Sosiologi Teks Pengantar dan Terapan. Jakarta: Kencana Prenada Media Group.

Prabowo, Fajar S A; Raden Aswin Rahadi; David vs Goliath. 2015. Uncovering The Future 
of Traditional Market in Indonesia, Mediterranean Journal of Social Sciences MCSER Publishing, Vo 6, N0 5

Pruitt,Dean G dan Jeffrey Z Rubin. 2004. Teori Konflik Sosial. Yogyakarta: Pustaka Pelajar.

Ridwan HR. 2002. Hukum Administrasi Negara. Yogyakarta: UII Press.

Ridwan. 2002. Hukum Administrasi Negara. Yogyakarta: UII Pres.

Sanderson, Stephen K. 2000. Makro Sosiologi Sebuah Pendekatan Terhadap Realitas Sosial. Jakarta: PT Raja Grafindo Persada.

Setiadi, Elly M. dan Usman Kolip. 2011. Pengantar Sosiologi Pemahaman Fakta dan Gejala Permasalahan Sosial: Teori, Aplikasi, dan Pemecahannya. Jakarta: Kencana Prenada Media Group.

Soehartono, Irawan. 2011. Metode Penelitian Sosial. Bandung: PT Remaja Rosdakarya.

Soekanto ,Soerjono. 1992. Sosiologi Suatu Pengantar. Jakarta: Rajawali Pers.

Soekanto, Soerjono dan Sri Mamudji. 2003. Penelitian Hukum Normatif. Jakarta: Rajawali Press.

Soekanto, Soerjono. 1986. Pengantar Penelitian Hukum. Jakarta: UI Press.

Soekanto, Soerjono. 1990. Sosiologi Suatu Pengantar. Jakarta: PT Raja Grafindo Persada.

Soetomo. 1995. Masalah Sosial dan Pembangunan. Jakarta: PT. Dunia Pustaka Jaya.

Sugiyono. 2008. Metode Penelitian Kuantitatif,Kualitatif dan $R \&$ D. Bandung: Alfabeta.

Sukri, M Fauzi. 2015. Pasar Minimarket. Surakarta: Joglosemar

Sun'an, Muammil. 2015. Ekonomi Pembangunan. Jakarta: Mitra Wacana Media.

Sunanto, Sandra., 2012. "Modern Retail Impact on Store Preference and Traditional Retailer in West Java”, Asian Journal of Business Research ISSN 1178-8933, Vol 2, No 2.

Sunanto,Sandra., 2012. "Modern Retail Impact on Store Preference and Traditional Retailers in West Java", Asian Journal of Business Research, ISSN 1178-8933, Vol 2, No 2.

Susan, Novri. 2011. Negara Gagal Mengelola Konflik (Tata Kelola Konflik di Indonesia). Yogyakarta: Pustaka Peajar.

Susilowati, Kartika Dewi Sri., 2014. "Dampak Pasar Modern Untuk Pedagang Tradisional (Kasus Di Kota Malang - Indonesia)”, International Journal of Technical Research dan Aplikasi e-ISSN: 2320-8163, Vol-2, Edisi Khusus 8, PP. 38-4438.

Sutopo,H.B.,. 2006. Metode Penelitian Kualitatif:Dasar Teori dan Terapannya Dalam Penelitian. Surakarta : Sebelas Maret University Press.

Utama, Yos Johan. 1995. Upaya Perlindungan hukum Bagi Masyarakat yang dilakukan oleh Peradilan Tata Usaha Negara. Semarang: Bahan Diskusi untuk Forum Fakultas Hukum Universitas Diponegoro.

Waluyo, Bambang. 1991. Penelitian Hukum Dalam Praktek. Jakarta: Sinar Grafika.

Wirawan. 2010. Konflik dan Manajemen Konflik (teori,Aplikasi dan Penelitian). Jakarta: Salemba Humanika.

\section{Sumber Internet :}

https://id.wikipedia.org/wiki/Pasar\#Pasar_tradisionald (diakses pada 14 Maret 2016 pukul 
18.30 WIB)

http://www.neraca.co.id/article/38397/ikappi-uu-perdagangan-lemahkan-pasar-tradisional (diakses pada diakses pada 14 Maret 2016 pukul 18.50 WIB )

http://news.analisadaily.com/read/menyoal-revitalisasi-pasar-tradisional/154409/2015/07/25 (diakses 14 Maret 2016 pukul 19.15 WIB)

https:/elitasuratmi.wordpress.com/2012/05/02/pengaruh-perkembangan-pasar-modern/ (diakses 14 Maret 2016 pukul 19:45 WIB)

http://kbbi.web.id/hak (diakses pada 7 Juni 2016 pukul $22.30 \mathrm{WIB}$ )

http://www.koran-sindo.com/news.php?r=5\&n=65\&date=2016-03-19 (diakses 10 Juni 2016 pukul 15.00 WIB) 